Cássia Barbosa Reis ${ }^{1}$

Sonia Maria Oliveira de Andrade ${ }^{2}$

Rivaldo Venâncio da Cunha ${ }^{3}$

Curso de Enfemagem, Universidade Estadual de Mato Grosso do Sul. Cidade Universitária Rod. Dourados/Itaum, Rural. 79804-970 Dourados MS. cassia@uems.br

2Centro de Ciências Biológicas e da Saúde, Câmara de Pesquisa e Pós-Graduação, Universidade Federal de Mato Grosso do Sul.

${ }^{3}$ Departamento de Clínica Médica, Faculdade de Medicina, Universidade Federal de Mato Grosso do Sul.

\title{
Aliados do A. Aegypti: fatores contribuintes para a ocorrência do dengue segundo as representações sociais dos profissionais das equipes de saúde da família
}

\author{
Allies of A. Aegypti: factors contributing to the occurrence \\ of dengue according to social representations \\ of professionals of family health teams
}

\begin{abstract}
Historically, health policies and actions to combat dengue have been based on vector control and field activities, while neglecting health education activities. Establishing the social representations of family health unit professionals about the factors that contribute to the sustained level of the occurrence rates of dengue is the scope of this research, in order to contribute to improved communication between health professionals and citizens, seeking to control the disease. A qualitative study was conducted with family health strategy professionals in six selected cities, with data tabulated by the Collective Subject Discourse technique. The results showed four discourses about the issues that were raised by the question of what caused the incidence of dengue. The conclusion drawn is that the professionals attribute the major share of responsibility for the incidence of dengue to the population, but also note the lack of structure and organization of services as well as perceiving difficulties for changes in observed behavior to occur with the resources available.
\end{abstract}

Key words Dengue, Health personnel, Family health, Prevention, Behavior
Resumo Historicamente as políticas de saúde e as ações de combate ao dengue são pautadas no controle vetorial, com atividades de campo, deixando em segundo plano as atividades de educação em saúde. Conhecer as representações sociais de profissionais de unidades de saúde da família, sobre os fatores que contribuem para a manutenção dos indices de ocorrência do dengue é o objetivo desta pesquisa de forma a contribuir para a melhoria da comunicação entre profissionais de saúde e população, visando o controle da doença. Foi realizado estudo qualitativo com profissionais da estratégia de saúde da família de seis municípios selecionados, sendo os dados tabulados pela técnica do Discurso do Sujeito Coletivo. Os resultados mostraram quatro discursos referentes a aspectos que foram levantados através da pergunta sobre qual a causa da ocorrência de dengue. Conclui-se que os profissionais atribuem à população parte importante da responsabilidade pela ocorrência do dengue, mas também observam a falta de estrutura e organização dos serviços, bem como percebem dificuldades para que ocorra a mudança dos comportamentos observados com os recursos disponíveis.

Palavras-chave Dengue, Profissional de saúde, Saúde da Família, Prevenção, Comportamento 


\section{Introdução}

Historicamente as políticas de saúde e as ações de combate ao dengue são pautadas no controle vetorial, com atividades de campo ${ }^{1-5}$. Entretanto, o controle do dengue deve ser multidirecionado, com ações voltadas também para o diagnóstico precoce, o tratamento adequado e a prevenção da disseminação do vírus.

No Brasil, o combate ao vetor, por ser causador de febre amarela, teve início entre 1902 e 1907, seguidos de programas de combate ao vetor, implantados nas décadas de 40 e 50, sendo considerado erradicado em 1955. Houve a reintrodução do mosquito em 1967, nova erradicação em 1973 e retorno em 1976 em função de falhas nas ações de controle e mudanças ambientais e sociais ocorridas neste período ${ }^{6}$.

Os autores supracitados fazem um resgate histórico dos programas de controle do dengue no Brasil, citando a elaboração, em 1996, do Plano de Erradicação do Aedes aegypti (PEAa), que, entretanto não conseguiu implementar todas as ações programadas, principalmente nas áreas de informação, educação e comunicação social.

Com a certeza de que a erradicação não era uma meta viável, a Fundação Nacional de Saúde (Funasa), responsável pela coordenação das ações de controle do dengue, elaborou o Plano de intensificação das Ações de Controle do dengue (PIACD/ 2001), seguido pelo Programa Nacional de Controle do dengue (PNCD/2002).

Paralelo aos programas de controle citados, o Ministério da Saúde implantou, em 1994, o programa de saúde da família (PSF). É uma estratégia que está em processo de constante mudança, atualmente implantado em 5.290 municípios, atingindo, no Estado de Mato Grosso do Sul, $100 \%$ dos 78 municípios, com cobertura populacional estimada de $61,3 \% 7$.

A ESF tem atividades voltadas para o controle do dengue nas ações de educação em saúde e mobilização social que estão inclusas nas atividades de trabalho dos agentes comunitários de saúde (ACS) como parte da estratégia adotada pelo $\mathrm{PNCD}^{1}$.

Entretanto, ações desenvolvidas por esses programas não foram capazes de controlar a ocorrência do dengue e assim sendo, conhecer as representações sociais de profissionais de unidades de saúde da família, sobre os fatores que contribuem para a manutenção dos índices de ocorrência do dengue é o objetivo desta pesquisa de forma a contribuir para a melhoria da comunicação entre profissionais de saúde e população, visando o controle da doença.

\section{Metodologia}

Este estudo tem desenho qualitativo descrito por Driessnack et al. $^{8}$ como forma de explorar temas pouco pesquisados na área de saúde ou onde a pesquisa quantitativa não parece ter produzido conhecimento adequado para responder a questões que envolvem aspectos subjetivos da realidade.

O marco teórico metodológico da presente pesquisa é a Teoria das Representações Sociais (TRS), proposta por Moscovici em 1961. Como parte da psicologia social, a TRS é um sistema de interpretação da realidade ${ }^{9}$, que se dá quando ocorre a interação e a comunicação desta realidade, onde estão implicados interesses humanos diversos ${ }^{10}$. Portanto, a forma de captar a representação social é a palavra, por excelência, uma vez que ela torna compreensível identificar as crenças, as imagens, as metáforas e os símbolos compartilhados coletivamente. Esses itens a serem identificados são pontos comuns na definição de vários autores, sendo que o próprio Moscovici ${ }^{9}$ afirma que toda representação é composta por linguagem e imagem, organizadas, socializadas e entendidas no contexto onde estão inseridos os indivíduos.

Para que haja atribuição de sentido para um determinado objeto e se forme uma representação social, duas figuras são descritas por Moscovici ${ }^{9}$, a objetivação e a ancoragem. Assim, a representação de um objeto ocorre em contato com a realidade já vivida que transforma o conteúdo e as percepções desse objeto. Nota-se que a relação é dialética, uma vez que a percepção do objeto também pode transformar a realidade do indivíduo e do seu meio.

$\mathrm{Na}$ emergência das RS existem fatores que favorecem seu surgimento como a presença de objetos que aparecem de diversas formas na sociedade e de grupos que mantém determinada relação com o objeto da representação. Associado a isso existem os valores que os grupos se apoiam para garantir sua identidade e coesão ("enjeu social"), a interação com outros grupos que determina estes valores e a ausência de um sistema ortodoxo ${ }^{11}$.

Dessa maneira, sinteticamente pode-se afirmar que as representações sociais são substratos verbais ou verbo-narrativos que são explicitados nos discursos e mostram o posicionamento individual sobre o tema pesquisado ${ }^{12}$.

Para apreensão da complexidade das RS, foi utilizada na coleta de dados a entrevista que privilegia a fala por meio dos discursos produzidos 
pelos entrevistados, favorecendo o diálogo e o acesso às opiniões ${ }^{13}$.

Os dados resultantes foram analisados considerando-se o Discurso do Sujeito Coletivo (DSC $)^{14}$, técnica que processa os discursos coletados, que em sua forma bruta são expressões individuais de uma concepção de mundo, para dar forma a uma RS, coletivamente construída.

O processamento dos discursos leva à construção do DSC que se dá de forma discursiva e não por categorização, utilizando-se, comumente de três figuras metodológicas: as expressões-chave, as ideias centrais e o DSC propriamente dito.

A identificação das expressões-chave semelhantes nos depoimentos é realizada através de sucessivas leituras do discurso de cada sujeito pesquisado. A expressão-chave é a figura metodológica que revela a essência do depoimento, é exatamente o que o sujeito falou sobre o tema ${ }^{14}$.

Apesar de os pesquisadores seguirem uma lógica bem definida na confecção da(s) questão(ões) norteadora (s) da sua pesquisa, a resposta do entrevistado, geralmente, segue lógica própria, o que faz com que encontremos expressões-chave sobre o tema diluídas em todo o discurso construído. Por isso a importância da leitura sucessiva e atenciosa dos dados para identificação de todas as expressões-chave que apresentem sentido e que melhor descrevem a mensagem emitida pelo entrevistado.

No momento da elaboração do seu discurso, o indivíduo está explicitando a sua representação social sobre o tema proposto, sendo que, na escala de complexidade da técnica, esta etapa está no primeiro nível e produz matéria prima riquíssima para a confecção do DSC.

De posse desses discursos individuais refletindo as representações sociais de um determinado grupo, devem ser identificadas as ideias centrais ali presentes, que constituem a segunda figura metodológica. É a forma mais sintética possível de descrever o sentido atribuído pelo entrevistado, ao assunto discutido. As ideias centrais semelhantes são selecionadas e a identificação da similaridade já pressupõe o agrupamento dessas ideias centrais de forma a construirmos o DSC ${ }^{12}$.

O DSC é a síntese, com sequência lógica, de todas as expressões-chave separadas em cada grupo de ideias centrais. Uma vez construído o DSC, tem-se uma série de dados processados que dará subsídios para uma análise fundamentada do tema. Neste sentido, o uso do DSC mostra-se bastante eficaz, já que a técnica sintetiza a opinião do grupo pesquisado e explicita tanto as fragilidades quanto as fortalezas do contexto avaliado.
Definiram-se como sujeitos da pesquisa os profissionais de saúde inseridos na ESF, das categorias médicos, enfermeiros e auxiliares de enfermagem. A escolha dos sujeitos foi pautada na premissa de que esses profissionais são a referência em saúde para a população da sua área de atuação e no entendimento de que as representações desses profissionais influenciam a sua forma de trabalhar e de se comunicar com os usuários dos serviços.

A seleção da amostra foi feita pela saturação das respostas definida como "o estado onde nenhum outro dado novo e relevante para o estudo emerge e os elementos de todos os temas, conceitos e teoria já foram considerados"8. Assim, as entrevistas foram feitas com todos os profissionais, sendo que, conforme cada categoria atingiu a saturação, ela foi eliminada da entrevista na próxima ESF.

O estudo foi realizado na microrregião de Dourados (MS). O Estado de Mato Grosso do Sul tem 78 municípios, sendo que, no processo de regionalização da saúde, foi dividido em três macrorregiões. A macrorregião de Dourados, situada na região sul, engloba 35 municípios, onde reside a quarta parte da população. Com exceção de Dourados, sede da macrorregião, todos os municípios são de pequeno porte. A macrorregião é dividida em quatro microrregiões, denominadas pelas suas sedes: Dourados, Naviraí, Nova Andradina e Ponta Porã.

A microrregião de Dourados é composta por 11 municípios com extensão territorial de 21.396 $\mathrm{km}^{2}$ que representa 5,99\% da área total do Estado.

Dourados é o segundo maior município do Estado de Mato Grosso do Sul, com 189.762 habitantes ${ }^{7}$. É um município que tem a agropecuária e o comercio como base econômica, com baixa taxa de desemprego e está em franco processo de desenvolvimento do seu parque industrial. É referência regional na área de saúde e a atenção básica está organizada em uma rede composta por unidades básicas (UB), unidades de saúde da família (USF), unidades de atendimento secundário e terciário. Existem 42 equipes de saúde da família (ESF), dessas cinco na área rural e duas na área indígena.

Os outros cinco municípios da microrregião de Dourados, selecionados para pesquisa são de pequeno porte (menos de 50.000 habitantes), com as mesmas características populacionais e econômicas de Dourados. Todos apresentam cobertura populacional de agentes comunitários de saúde acima de $70 \%$, com quatro ou mais unidades de saúde da família implantadas. 
A coleta de dados foi realizada em todas as Unidades de Saúde da Família (USF) desses seis municípios durante o segundo semestre de 2010.

O presente estudo seguiu as Diretrizes e Normas de Pesquisa Envolvendo Seres Humanos ${ }^{15}$, aprovado pelo Comitê de Ética de Pesquisa em Seres Humanos da Universidade Federal de Mato Grosso do Sul.

\section{Resultados e discussão}

Foram entrevistados 12 médicos (26,6\%), 16 enfermeiros $(35,6 \%)$ e 17 auxiliares de enfermagem (37,8\%), com média de idade de 39,95 anos, sendo a maioria na faixa etária de 31 a 50 anos $(57,8 \%)$. Mais de um terço são do sexo feminino $(75,5 \%)$.

Fatores relacionados

aos macrodeterminantes em saúde

Os DSC confeccionados a partir das falas dos entrevistados das categorias profissionais médicos, enfermeiros e auxiliares de enfermagem que respondem a questão norteadora sobre quais são os fatores que contribuem para a ocorrência do dengue, mostram quatro ideias centrais (IC) descritas na Tabela 1.

Em relação à IC que relata a falta de cuidado com o ambiente, encontra-se no DSC 1 , aspectos sobre o descaso da população com o seu entorno, o comodismo, hábito e cultura e a resistência da população às orientações recebidas dos profissionais das ESF.

Conforme descrito na Tabela 1, houve 100\% de citações desses aspectos entre os enfermeiros e percentuais não inferiores a $65 \%$ nas outras categorias profissionais. Observa-se que a responsabilização da população em relação ao cuidado com o ambiente é ideia concreta nas RS dos profissionais entrevistados.
DSC 1 - Falta de cuidado da população com o ambiente em que vive

Eu acho que a população não se conscientizou ainda com as questões que os ovos permanecem lá. Elas não acreditam e quando acreditam são desleixadas. Mas porque, sendo que tem coleta? Então o que falta é uma conscientização da população e poder público. Parece uma negação, né? Porque quando a gente ta na campanha de coletar, de distribuir saco de lixo, ta todo mundo empenhado em estar coletando e tudo. Então quando acontece uma diminuição a população acaba se esquecendo, acaba deixando de lado um pouco. Com certeza o município também tem parte porque tentando diminuir os casos lançou mão de algumas estratégias, e ai a estratégia levou o povo ao comodismo... agora pra tirar tá difícil. Isso é do ser humano, se acomodar: deixa as vasilhas de boca pra cima e fica. Mesmo ele esclarecido ele é incapaz de virar uma lata com água. É um fator cultural. Eu acho que é um pouco da cultura mesmo do brasileiro de deixar se prejudicar né? Só se preocupa na hora que está em cima de uma cama, enfermo. Porque, às vezes, não é só o fumacê que vai resolver o problema do dengue, mas o que vai resolver mesmo é a educação, mudança de hábitos, é a população se envolver. Ah, eu acho que na realidade muitos já nascem dessa forma. A cultura, essa cultura que eu to falando, num to falando nem só a dengue, mas a cultura de não cuidar, de não ficar atento, atinge todas as classes sociais. Tem algumas famílias que são resistentes. Porque quando você fala do dengue ela já acha que na casa dela não tem. Se a gente tem resistentes nessa área a gente continua tendo dengue.

Observa-se uma correlação direta entre o fato de que a população não acredita nas informações técnicas sobre dengue e o comportamento desleixado em relação ao cuidado com o meio ambiente. Ao descuido com o micro-espaço, atribui-se o desconhecimento ou a baixa conscientização do papel individual na construção do coletivo. Este descaso generalizado é descrito por Boff ${ }^{16}$ como

Tabela 1. Frequência absoluta e relativa das causas apontadas por profissionais da Estratégia de Saúde da Família para ocorrência de dengue. Microrregião de Dourados, 2010.

\begin{tabular}{|c|c|c|c|c|c|c|c|c|}
\hline \multirow[t]{2}{*}{ Ideias Centrais } & \multicolumn{2}{|c|}{$\begin{array}{c}\text { Médicos } \\
(\mathrm{n}=12)\end{array}$} & \multicolumn{2}{|c|}{$\begin{array}{l}\text { Enfermeiros } \\
\quad(n=16)\end{array}$} & \multicolumn{2}{|c|}{$\begin{array}{l}\text { Auxiliares de } \\
\text { enfermagem } \\
(n=20)\end{array}$} & \multicolumn{2}{|c|}{$\begin{array}{c}\text { Total } \\
(n=48)\end{array}$} \\
\hline & $\mathbf{n}$ & $\%$ & $\mathbf{n}$ & $\%$ & $\mathbf{n}$ & $\%$ & $\mathbf{n}$ & $\%$ \\
\hline Falta de cuidado com o ambiente & 8 & 66,7 & 16 & 100,0 & 13 & 65,0 & 37 & 77,1 \\
\hline Descrédito na ocorrência e na gravidade da doença & 10 & 83,3 & 10 & 62,5 & 10 & 50,0 & 30 & 62,5 \\
\hline Serviços diretos e relacionados ao controle da dengue & 7 & 58,3 & 8 & 50,0 & 9 & 45,0 & 24 & 50,0 \\
\hline Situação socioeconômica da comunidade atendida & - & - & 5 & 31,3 & 6 & 30,0 & 11 & 22,9 \\
\hline
\end{tabular}


um dos sintomas da crise civilizacional e que enfatiza a necessidade do cuidado com a terra nos pequenos detalhes do nosso cotidiano.

A referência à falta de conscientização da população perpassa todo o discurso, mas é importante frisar que essa conscientização, tão necessária na ótica dos profissionais, não é um processo simples, já que a experiência da doença é fator preponderante para formar o que Bosi e Affonso $^{17}$ chamam de "consciência preventiva". Esta não ocorre só porque existe um saber que é passado dos profissionais para a população, mas decorre de sua experiência com a saúde e a doença. Assim, a orientação e, muitas vezes, a limpeza realizada pela equipe de saúde, não leva a uma postura permanente de conservação do meio e consequente formação de hábitos higiênicos. Marzocki ${ }^{18}$ enfatiza que é um grande desafio manter a população motivada, principalmente em casos em que a doença tem ocorrência endêmica e esporádica. Associado a isso temos as ações de planejamento do PNCD, verticalizado e não integrado, que não incentiva adequadamente a mudança efetiva de comportamento da população para ações de prevenção e controle da doença. A ausência, no DSC, de aspectos relacionados à amplitude de conhecimentos da população mostra o quanto o profissional ainda precisa incorporar os diversos conceitos que formam a consciência coletiva.

Essa dificuldade em "tomar consciência" atribuída à população é explicada no DSC como uma "negação" de sua responsabilidade em relação ao meio ambiente. O processo de negação do aprendido passa pela lógica Aristotélica do "ou é ou não é” onde uma coisa é sempre contrária a outra, mas que não significa que um ou outro sejam necessariamente falsos ou verdadeiros ${ }^{19,20}$.

Assim, pela lógica dos profissionais, os quintais estão sempre sujos porque existe certa negação da necessidade real de manutenção a limpeza, que deve ser realizada pelos agentes públicos e não são entendidas como responsabilidade individual. Mas, a manutenção constante da higiene ambiental é fator preponderante para a prevenção de epidemias e diminuição dos riscos de transmissão do dengue ${ }^{21}$.

O DSC aponta o comodismo como uma característica humana, generalizando este conceito para toda população. Os profissionais atribuem esta acomodação às políticas assistenciais implantadas para a prevenção e controle do dengue. Quando se verifica o histórico dessas políticas e programas $^{6}$, observa-se que, até a edição do PNCD, as ações foram todas voltadas para a er- radicação do vetor, ainda que, a partir do Programa de Erradicação do Aedes aegypti (PEAa I), existisse o componente Informação, Educação e Comunicação (IEC), não efetivamente implantado. Ainda que o PNCD passasse a ter foco no controle e não na erradicação do Aedes aegypti, as ações de educação em saúde são baseadas no repasse de informações para a população sobre prevenção e tratamento do dengue. Assim, as ações não alcançaram mudanças comportamentais, apresentando para a população um cenário assistencialista, o que explica a RS do profissional quando atribui à política de saúde a acomodação da população em relação ao dengue. Ressalta-se, neste DSC, a percepção da dificuldade de reverter esta situação, uma vez que o setor saúde não consegue atingir aspectos do comportamento humano. Reafirma-se aqui a importância da valorização da consciência preventiva ${ }^{14}$ para comportamentos. Vale lembrar que é exatamente esta mudança comportamental o objetivo do "Communication and marketing integrated for behavior impact” (COMBI), metodologia proposta pela Organização Panamericana de Saúde (OPAS) após estudos realizados em diversos países a partir de $2.000^{4,22}$.

Ainda que tenha havido um esforço no sentido de capacitar os países para o desenvolvimento desta metodologia, a implantação no Brasil é incipiente, iniciando-se através de um projeto piloto em 2004 para ser desenvolvido em quatro municípios de estados distintos nas regiões nordeste, sudeste e sul. Segundo avaliação de Bra$\mathrm{ga}^{22}$, as ações foram planejadas para trabalhar componentes particulares do controle do dengue atingindo apenas parcialmente os objetivos propostos para mudança de condutas. Existe premente necessidade de investimentos em metodologias adequadas a mudanças de comportamento de forma a garantir ações sustentáveis em médio e em longo prazo ${ }^{6}$. Esta conclusão não foi referida pelos entrevistados e apresentaram ainda outras causas para o comodismo: falta de educação da população, falta de perspectiva de vida e individualismo.

Quando citada a falta de educação, parece referir-se a educação informal, recebida da família e do meio social. É mais uma colocação de maus hábitos do que propriamente o que se entende por falta de educação formal. O que falta é a educação para a cidadania.

Outro fator apontado como causa da ocorrência de dengue é a cultura. Laraia ${ }^{23}$ apresenta a evolução do conceito de cultura através dos tempos e traz a ideia de que "culturas são sistemas 
(padrões de comportamento socialmente transmitidos) que servem para adaptar as comunidades humanas aos seus embasamentos biológicos", e enfatiza que o conceito de cultura está em constante reformulação já que se refere à compreensão da natureza humana. Esta adaptação opera interferindo no plano biológico como expresso no DSC que atribui à cultura a falta de cuidado e de compromisso da população com o seu entorno, o que leva a um ambiente propício para a manutenção de criadouros do Aedes aegypti.

A ideia da imutabilidade da cultura, expressa no DSC dificulta as proposições de mudanças que os profissionais de saúde acreditam necessárias e vem de encontro com o que Laraia ${ }^{23}$ chama de troca de padrões culturais, ou seja, a cultura é dinâmica e, portanto, mutável.

Observa-se que no DSC aparece a cultura como um fator homogêneo em relação às classes sociais, ou seja, não cuidar do ambiente está na cultura de pobres e ricos.

Em todo DSC as palavras cultura e hábitos são citadas como sinônimos.

Habito é uma palavra derivada do latim habere, termo genérico utilizado por Aristóteles que o dividia em hábitos intelectuais e hábitos morais. Hábito refere-se à adaptação mental para reagir de forma idêntica a um determinado estímulo $^{24}$. É uma tendência adquirida e não um determinismo biológico. Observa-se que o habito pode adquirir características boas ou más, referentes a concepções morais de cada uma das ações referidas. Quando, no DSC, aparece hábito, está se referindo na verdade a concepção moral de mau hábito o que nos remete à necessidade de mudança de hábito, considerada difícil para os entrevistados já que tudo está associado à cultura imutável ou de difícil acesso pelos meios disponíveis aos profissionais.

É importante que os profissionais entendam essas diferenças e que cultura é essencial na formação da identidade individual e comunitária. Importante também se faz diferenciar os tipos de hábitos de forma a planejar ações para mudar os que são prejudiciais e propiciem o aparecimento de reservatórios do Aedes aegypti.

Os profissionais entrevistados sentem, em alguns casos, que a família apresenta barreiras para a realização da visita domiciliar, quando o assunto é dengue. Este assunto envolve aspectos que são difíceis de abordar como, por exemplo, higiene e formas de cuidado no armazenamento de vasilhames. Uma primeira abordagem inadequada, normativa e enfática demais pode propiciar resistência a ações posteriores.
No DSC sobre a ocorrência do dengue aparece esta dificuldade, já que na visão do usuário a casa pode não estar "tão suja" assim que precise de intervenção externa.

As primeiras intervenções necessitam desses cuidados colocados no final do DSC, com uma introdução do tema depois de conhecer o ambiente da família para não "afugentar" e dificultar o trabalho dos agentes de saúde ${ }^{22}$. Entretanto, nos casos onde a barreira já se instalou, tornasse necessário uma abordagem direta para descobrir a causa do problema, fazendo a família entender e, principalmente, participar das ações de prevenção e controle do dengue.

Volta aqui à ênfase nas ações que propiciem mudanças de conduta ${ }^{4}$ para que as atividades de comunicação possam influenciar, e posteriormente reforçar a decisão, a conduta e a norma social em relação à prevenção do dengue.

Existem, entretanto, outros aspectos que não foram levantados neste discurso em relação a esta resistência ao trabalho da equipe de saúde: a falta de empatia da população com a própria equipe e a perspectiva negativa da visita domiciliar. Estabelecer vínculo e manter a relação com a família é um grande desafio profissional que precisa ser enfrentado para que haja acolhimento de ambas as partes ${ }^{25}$. A perspectiva negativa, segundo Sakata et al. ${ }^{26}$, refere-se ao caráter de fiscalização e vistoria da visita domiciliar, muito caracterizado no caso do dengue. Esse controle sobre a vida e o ambiente das pessoas pode produzir um distanciamento entre família e profissional se o visitado entender que está limitando sua privacidade e sua autonomia.

\section{DSC 2 - Descrédito da população}

\section{na ocorrência e na gravidade da doença}

A dengue já se tornou uma coisa comum, que vai continuar acontecendo é uma moda. Eles acham que porque mosquitinho pequenino, ele não é tudo isso que a gente fala e que a TV fala um pouco é pra assustar. É muito de graça, não dá valor. Acreditam só depois que estão doentes. $O$ que precisa é que a sociedade inteira entenda que tem que ser uma luta de todo mundo. A questão é que, principalmente porque a dengue tem uma boa taxa de cura, a dengue não está levando à morte, igual à gripe A. Como em geral adoecem muitas pessoas, mas nunca teve um número de mortos expressivos, as pessoas não se preocupam, acha que é uma doencinha assim. Mesmo sabendo que tem risco de morte, acaba banalizando, como coisa comum. Então eu acho que quem nunca teve dengue minimiza a doença. 
Os profissionais entendem que a população não acredita na ocorrência da doença por esta ter caráter benigno. Esta representação também foi relatada por Fiqueiró et al. ${ }^{27}$, bem como a descrição de sua inevitabilidade.

A descrição de "doença da moda" evidencia o conhecimento sobre seu ciclo biológico, mas não sobre sua importância. Santos et al. ${ }^{28}$ também chegaram a esta conclusão, o que agrava o fato de que não apresentam atitude adequada na prevenção e controle do dengue.

Sabe-se que, independente da sua situação geográfica e socioeconômica, qualquer pessoa tem risco de ser picada pelo Aedes aegypti e desenvolver a dengue. Entretanto, esta evidencia não encontra reflexo na população, pela visão dos profissionais. É interessante notar que existe uma generalização em relação a este "descrédito na ocorrência”, já que parece ser um descrédito de toda população e não só de uma parte que não adota medidas de prevenção.

Existe concordância entre os estudos realizados sobre conhecimento da população de que a taxa de acerto em inquéritos feitos sobre o vetor e a doença é alta, mas que isto não se reflete na prática. É necessário um processo de abstração bastante elaborado para entender como um vírus, ser invisível, pode causar transtornos tão intensos. Partindo desta constatação, fica mais difícil motivar a necessidade de autocuidado e a mudança de atitude, mesmo porque, como aponta Ferreira ${ }^{29}$ uma das premissas a se considerar para o trabalho em educação e mobilização social em saúde é que "não se pode cuidar da saúde do outro, se este não quer fazê-lo por si mesmo". E só consegue-se fazer a população querer algo quando ela entende a necessidade das ações. Neste DSC aparece também a representação sobre as políticas assistencialistas para reforço do fato de que se a doença é benigna e a assistência é gratuita não existe porque temê-la.

Uma ideia que perpassa, não só este, mas em vários outros DSC, é a individualidade das atitudes. A cidadania é outro conceito que precisa ser trabalhado nas atividades educativas para que se possa pensar em coletividade. O DSC propõe ainda o trabalho em sociedade, em grupo para entender que a luta contra dengue é coletiva. Para tanto é importante que todos entendam que a ocorrência da doença é universal e as ações de prevenção e controle são de responsabilidade compartilhada de população e instituições, sejam elas publicas ou privadas.

No DSC a RS de que a dengue é uma doença corriqueira e benigna está bem definida. Isso faz com que a população também não acredite na sua gravidade. Santos et al. ${ }^{28}$ evidenciam o conhecimento ineficiente quanto à gravidade da doença, mas é crescente a frequência de manifestações não usuais e graves ${ }^{20}$, bem como o aumento dos óbitos ocorrido nos últimos anos. Neste sentido, o DSC aponta a cobertura dos meios de comunicação como difusores de alertas sobre o H1N1, sem dar a mesma ênfase para os dados alarmantes e crescentes de óbitos por dengue.

\section{DSC 3 - Qualidade dos serviços diretos} e dos relacionados ao controle do dengue

Como o município não está coberto nem uns 70\% por PACS ou PSF como deveria estar, existe assim uma baixa atividade educativa. E eu acho que o poder público pega muito leve com essas pessoas que são donos de terrenos baldios, e tem aquele lixão a céu aberto. Uma parceria diminuída do setor de serviços urbanos. Tinha, por exemplo, locais que juntavam lixo, mas a prefeitura não foi retirar. Então eu acho que o poder público também falhou. Por exemplo, houve aquela reforma da Sanesul onde se fizeram muitos buracos, deixaram muitas coisas que juntavam muita água. Não adianta você querer botar defumador e ter entulho jogado por aí, continua não cuidando do foco que é a água parada! Até porque, você vê nesses órgãos públicos aquelas plantas que junta água. Nós recebemos treinamentos pontuais, e tudo aquilo que a gente conhece é que a gente vai atrás de ler, procurar se informar, mas realmente falta, há deficiência. É dificultando porque se o profissional não ta bem capacitado pra falar sobre o assunto, ele não vai ter certeza, convencimento, na hora de que ele vai ta passando orientação. Não estamos sabendo educar.

Diversos itens referentes à estrutura dos serviços de saúde e de serviços públicos municipais foram citados como deficientes e causa básica da ocorrência do dengue na região.

Ainda que os dados mostrem uma cobertura populacional média de ESF acima de $77 \%$ nos municípios da microrregião de Dourados, o fato de que existem áreas descobertas foi identificado como fator importante, já que esta estratégia é considerada como prioritária para a prevenção e o controle do dengue. Zambrini ${ }^{30}$ entende que a ênfase na assistência prestada pela atenção básica é essencial para a eficácia dos programas de controle, citando a diferença entre os índices de infecção do dengue no Rio de Janeiro e Niterói.

A presença de lixo a céu aberto e terrenos baldios utilizados como depósito de lixo também foi identificado como falha de estrutura e de fiscalização por parte dos órgãos responsáveis, sen- 
do que a parceria entre os diversos setores do poder público não é uma realidade, propiciando atraso nas solicitações de limpeza e nas ações que necessitam de apoio logístico.

Uma observação importante no DSC é a presença de bromélias nos prédios públicos. Os profissionais entendem que os responsáveis pelos setores devem ter atitudes exemplares na eliminação de possíveis criadouros do Aedes aegypti. Cunha et al. ${ }^{31}$ apresentam os resultados de estudo que mostra que o hábito de cultivar bromélias em domicílios como planta decorativa evidencia um micro-habitat importante para abrigar formas imaturas do Aedes aegypti, principalmente as bromélias que sofreram ação antrópica, geralmente as mais usadas na decoração de jardins.

Percebe-se a ansiedade dos profissionais em transmitir a informação correta e atualizada sobre a dengue para a população. Não estar adequadamente capacitado sobre o assunto gera insegurança e a impressão de que não conseguem convencer os usuários. Esta ausência de capacitação formal, tendo apenas repasse de informações fragmentadas e descontinuadas de forma verticalizada, faz com que as ações educativas fiquem restritas e demonstrem a fragilidade do serviço. Cardoso e Nascimento ${ }^{32}$ acrescentam ainda o caráter autoritário deste repasse de informações, realizado por setores específicos das secretarias de saúde. Ainda que as discussões teóricas sobre educação em saúde e educação popular estejam bastante desenvolvidas, a prática ainda é pautada no repasse de informações, atingindo assim tanto os profissionais de saúde como a própria população ${ }^{33}$.

Zambrini ${ }^{30}$ coloca que existe um alto grau de improvisação entre os atores envolvidos nestas ações, concordando com Alves e Aerts ${ }^{34}$ que mostrou a dificuldade dos profissionais em fazer educação popular em saúde. Esta improvisação está presente no DSC e mostra o quanto a capacitação dos profissionais, nos diversos aspectos do dengue, pode ajudar em futuras epidemias e mesmo no maior controle nos períodos interepidêmicos.

Nota-se também certa insatisfação com o direcionamento das políticas de saúde nos municípios da região, que menosprezam a importância de capacitação específica para melhorar o impacto das ações e diminuir a ocorrência de dengue.

Quando os profissionais colocam no DSC que não estão sabendo educar, estão se referindo não só a transmissão de conteúdos específicos sobre a biologia do vetor, formas de prevenção e controle, identificação de sinais, sintomas e gravidade do dengue. Parecem querer dizer da dificuldade metodológica de conseguir alcançar a população com objetivo de proporcionar mudanças efetivas. Para tanto, mais que adquirir conhecimentos sobre a doença e seu vetor, é imprescindível conhecer e dominar os métodos didáticos para trabalhar populações específicas; ter noções de história, sociologia e relações humanas, entre outras. Ou seja, ter olhar ampliado para questões que vão muito além da biologia, patologia e tratamento do dengue. Desta forma, torna-se importante que se desenvolvam relações horizontais entre profissionais e usuários dos serviços de saúde para que as ações sejam complementares para efetiva prevenção da dengue ${ }^{34}$.

DSC 4 - Influência das classes sociais na ocorrência e no controle do dengue

A dengue é uma doença socioeconômica. Eu já percebi que não tem isso de "mais pobre e de quem tem mais dinheiro", é "cuida mais ou cuida menos”. Por exemplo, essa região aqui tem mais condições de moradia, facilidades de vias públicas também. Já no outro bairro, além de não ter emprego, eles tinham um tipo de atividade que juntava lixo e a quantidade de coisas para se cuidar é maior. Sem contar também, a gente via muito terreno baldio lá. Mas foi encontrado larvas na classe $C$, na classe A, na classe E, na classe B. Mas aquela população parece que era mais assim. Receptiva, você reunia, eles iam. Aqui é difícil reunir sabe, porque todo mundo trabalha, lá geralmente é só o pai que trabalha e tem casas que os agentes não conseguem estar entrando, tem gente que recebe no portão e não deixa entrar. E realmente trata mal o agente de saúde.

Os profissionais associam a estrutura disponível nos bairros mais centrais com a menor ocorrência de dengue, ainda que façam isso de forma totalmente empírica, sem citar dados epidemiológicos que comprovem esta associação. Entretanto, citam a estrutura das ruas, casas e saneamento como fatores que contribuem para que haja menor numero de criadouros.

Por consequência, associam as condições sanitárias e socioeconômicas de bairros periféricos com a presença de criadouros importantes, principalmente aqueles relacionados ao lixo. Ainda que façam a diferenciação da estrutura dos bairros, a representação presente é de que mesmo sendo uma doença socioeconômica, ela afeta a todas as classes sociais e podem ser encontrados criadouros espalhados por toda extensão dos municípios. Ou seja, a condição socioeconômica e de moradia é fator determinante, mas não condicionante na ocorrência do dengue $e^{5}$. 
O DSC apresenta ainda as dificuldades encontradas para que a população aceite a presença da equipe em qualquer contexto. A participação da população é importante para promover aceitabilidade dos profissionais, factibilidade das ações e apropriação dos conceitos de prevenção e controle do dengue, propiciando assim a parceria na execução das ações ${ }^{35}$.

\section{Considerações finais}

Conclui-se que os profissionais atribuem à população parte importante da responsabilidade pela ocorrência do dengue, mas também observam a falta de estrutura e organização dos serviços para atender melhor, bem como percebem dificuldades para que ocorra a mudança dos comportamentos observados com os recursos dis- poníveis. Considera-se importante a divulgação das percepções dos profissionais, principalmente no que se refere a conceitos equivocado de forma que haja a valorização de capacitação contínua e contextualizada, bem como a implantação de metodologias que apresentem impacto no comportamento de profissionais e população na prevenção e combate ao dengue. Os discursos apresentados evidenciam a importância de uma mudança de conduta que parta dos níveis decisórios de gestão, que incluam a opinião e a percepção de profissionais e usuários e que discuta conceitos pouco trabalhados nos cursos de formação profissional na área de saúde, de forma a conseguir impactar conduta, conforme objetivos preconizados pela Organização Pan-americana de Saúde através da Estratégia de Gestão Integrada para Dengue (EGI-Dengue).

\section{Colaboradores}

CB Reis e SMO Andrade trabalharam em todas as etapas do artigo. RV Cunha trabalhou na concepção, revisão critica e aprovação da versão a ser publicada. 


\section{Referências}

1. Brasil. Ministério da Saúde (MS). A sociedade contra a dengue. Brasília: MS; 2002.

2. Penna MLF. Um desafio para a saúde pública brasileira: o controle do dengue. Cad Saude Publica 2003; 19(1):305-309.

3. Lefèvre F, Lefèvre AMC, Scandar SAS, Yassumaro S. Representações sociais sobre relações entre vasos de plantas e o vetor do dengue. Rev Saude Publica 2004; 38(3):405-414.

4. Parks W, Lloyd L. Planificación de la movilización y comunicación social para la prevención y el constrol del dengue: guia paso a paso. Organización Mundial de la Salud: Ginebra; 2004.

5. Torres EM. Dengue. Rio de Janeiro: Fiocruz; 2005.

6. Braga IA, Valle, D. Aedes aegypti: histórico do controle no Brasil. Epidemiologia e Serviços de Saúde 2007; 16(2):113-118.

7. Ministério da Saúde. Evolução da cobertura populacional da Estratégia da Saúde da Família. 2011. [acessado 2011 maio 8]. Disponível em: http:// dab.saude.gov.br/abnumeros.php

8. Driessnack M, Souza VD, Mendes IAC. Revisão dos desenhos de pesquisa relevantes para enfermagem: parte 2: desenhos de pesquisa qualitativa. Rev Latino Americana de Enferm 2007; 15(4):684-688.

9. Moscovici S. A representação social da psicanálise. Rio de Janeiro: Zahar; 1978.

10. Moscovici S. Representações sociais. Investigações em psicologia social. 6a Edição. Petrópolis: Vozes; 2009.

11. Almeida AMO, Santos MFS, Trindade ZA, organizadores. Teoria das representações sociais 50 anos. Brasilia: Technopolitik; 2011. Coedicação Centro Moskovisci/UnB.

12. Lefèvre F, Lefèvre AMC, Marques MCC. Discurso do sujeito coletivo, complexidade e auto-organização. Cien Saude Colet 2009; 14(4):1193-1204.

13. Fraser MTD, Gondin SMG. Da fala do outro ao texto negociado: discussões sobre a entrevista na pesquisa qualitativa. Paidéia 2004; 14(28):139-152.

14. Lefèvre F, Lefèvre AMC. $O$ discurso do sujeito coletivo: um novo enfoque em pesquisa qualitativa (desdobramentos). Caxias do Sul: EDUCS; 2003.

15. Brasil. Ministério da Saúde (MS). Normas de pesquisa envolvendo seres humanos - Resolução 196 96. Informe Epidemiológico do SUS 1996; 2(Supl. 3):13-30.

16. Boff L. Saber cuidar. Ética do humano - compaixão pela terra. 5a Edição. Petrópolis: Vozes; 1999.

17. Bosi MLG, Affonso KC. Cidadania, participação popular e saúde: com a palavra os usuários da rede pública de serviços. Cad Saude Publica 1998; 14(2): 355-365.

18. Marzochi KGF. Dengue endêmico: desafio das estratégias de vigilância. Rev Soc Bras Med Tropical. 2004; 37(5):413-415.

19. D'agord M. A negação e a lógica do sujeito. Ágora 2006; 9(2):241-258.

20. Souza EC. Negação e diferença em Platão. Tranformação Formação Ação. 2010; 33(1):1-18.

21. Guzmán MG, García G, Kouri G. El dengue y el dengue hemorrágico: prioridades de investigación. Rev Pananam Salud Publica 2006; 19(3):204-215.
22. Braga IA. Avaliação da efetividade da utilização da metodologia Communication and marketing integrated for behaviour impact-COMBI para o controle do dengue em duas localidades do Brasil [dissertação]. Brasilia: Universidade de Brasília; 2008.

23. Laraia RN. Cultura: um conceito antropológico. $21^{\mathrm{a}}$ Edição. Rio de Janeiro: Zahar; 2007.

24. Farias PL. Semiótica e cognição: os conceitos de hábito e mudança de hábito em CS. Pierce. Revista Eletrônica Informação e Cognição 1999; 1(1):12-16.

25. Marcon SS, Oliveira RG. Trabalhar com famílias no Programa de Saúde da Família: a prática do enfermeiro em Maringá-Paraná. Rev Escola de Enferm da USP 2007; 41(1):65-72.

26. Sakata KN, Almeida MCP, Alvarenga AM, Craco PF, Pereira MJB. Concepções da equipe de saúde da família sobre visitas domiciliares. Rev Bras Enferm 2007; 60(6):659-664.

27. Figueiró AC, Sóter AP, Braga C, Hartz ZMA, Samico I. Análise lógica de intervenção do Programa Nacional de Controle do dengue. Rev Bras Saúde Materno Infantil 2010; 10(Supl. 1):S93-S106.

28. Santos SL, Cabral ACSP, Augusto LGS. Conhecimentos, atitudes e práticas sobre dengue, seu vetor e ações de controle em uma comunidade urbana do Nordeste. Cien Saude Colet 2011; 16(Supl. 1):13191330.

29. Ferreira FS. Educação em saúde no controle do dengue no Brasil, 1998 a 2004: reflexões sobre a produção científica [dissertação]. Rio de Janeiro: Fiocruz; 2006.

30. Zambrini DAB. Lecciones desatendidas entorno de La epidemia de dengue em Argentina, 2009. Rev Saude Publica. 2011; 45(2):428-431.

31. Cunha SP, Alves JRC, Lima MM, Duarte JR, Barros LCVL, Silva JL, Gammaro AT, Monteiro Filho OS, Wanzeler AR. Presença do Aedes aegypti em Bromeliaceae e depósitos com plantas no município do Rio de Janeiro. Rev Saude Publica 2002; 36(2):244245.

32. Cardoso AS, Nascimento MC. Comunicação no Programa de Saúde da Família: o agente de saúde como elo integrador entre a equipe e a comunidade. Cien Saude Colet 2010; 15(Supl. 1):1509-1520.

33. Silva CMC, Meneghim MC, Pereira AC, Mialhe FL. Educação em saúde: uma reflexão histórica de suas práticas. Cien Saude Colet 2010; 15(5):2539-2550.

34. Alves GG, Aerts D. As práticas educativas em saúde e a Estratégia de Saúde da Família. Cien Saude Colet 2011; 16(1):319-325.

35. Castro M, Pérez D, Pérez K, Polo V, Lópes M, Sánchez L. Contextualizacion de uma estratégia comunitária integrada para la prevencion del dengue. Revista Cubana de Medicina Tropical 2008; 60(1).

Artigo apresentado em 106/2011

Aprovado em 25/08/2011

Versão final aprovada em 15/09/2011 